\title{
Low-Cost Solution for Assessment of Urban Flash Flood Impacts Using Sentinel-2 Satellite Images and Fuzzy Analytic Hierarchy Process: A Case Study of Ras Ghareb City, Egypt
}

\author{
Mohammed Sadek (iD) and Xuxiang Li (D) \\ School of Human Settlements and Civil Engineering, Xi'an Jiaotong University, Xi'an 710049, China \\ Correspondence should be addressed to Xuxiang Li; hupo0311@hotmail.com
}

Received 1 November 2018; Revised 7 March 2019; Accepted 17 March 2019; Published 2 May 2019

Academic Editor: M. Shahria Alam

Copyright (c) 2019 Mohammed Sadek and Xuxiang Li. This is an open access article distributed under the Creative Commons Attribution License, which permits unrestricted use, distribution, and reproduction in any medium, provided the original work is properly cited.

\begin{abstract}
Natural hazards are indeed counted as the most critical challenges facing our world, represented in floods, earthquakes, volcanoes, hurricanes, and forest fires. Among these natural hazards, the flash flood is regarded the most frequent. In this work, we utilized two Sentinel-2 satellite images, before and after the flash flood, SRTM and photos captured by using a helicopter. This paper aims at three prime objectives. Firstly, the flood influence is determined on the city of Ras Ghareb, Egypt, based on analyzing free satellite data (Sentinel-2 images). Secondly, fuzzy the analytical hierarchy process (FAHP) method and a geographical information system (GIS) are integrated for flood risk analysis and evaluation in the flood-prone area. Finally, such a flood vulnerability map is used as an index to assist the decision-makers prepare for probable flooding. FAHP is preferable as it can cater to the uncertainties in data and analysis. As a result, FAHP is appropriate to determine the flood-vulnerable area in cities especially due to the matching with the most destroyed areas identified by the change detection between the two Sentinel-2 images. Then, the decisionmaker can depend on Sentinel-2 images to estimate the flood influence through a regional scale or applying the FAHP on cities susceptible to flash floods in case of unavailable satellite images to contribute in establishing an early warning system enough to the evacuation of the risky areas.
\end{abstract}

\section{Introduction}

Urban flooding has been recently one of the most critical problems in the world due to its frequent occurrence which leads to infrastructure damage and people death. The flash flood in an urban area is identified by the comparatively short period of ephemeral water flow, scarcely takes more than one day [1]. The first step of flood management is the obtainment of the latest update of the hazard maps. Flood hazard mapping contributes the basis of the decisionmaking process by enriching the knowledge essential for understanding the nature and the characteristics of flooding to avoid the danger in a community or a city.

Mapping and modelling the areas influenced by floods is a crucial mission so as to (i) identify the most sensitive zones for civil protective actions, (ii) assess damages, and (iii) make valid urban planning [2]. Accordingly, this paper seeks to assess the impacts of the urban flash flood based on low-cost solution and applying a mathematical technique to simulate the area prone to the flood.

Advances in remote sensing data and computer science have allowed rapid and accurate mapping of the flood impacts and their models during or a short time after the flood event at different spatial and temporal resolution using multispectral or synthetic aperture radar (SAR) images $[3,4]$. Compared to traditional surveying techniques, modern remote sensing can provide overall and continuous coverage of the flood event, which assists the flood monitoring and damage assessment $[5,6]$. The remote sensing data consist of spaceborne and airborne imageries employed for flood mapping.

The spaceborne data (optical and radar) have vastly been utilized to delineate the inundation areas with high accuracy $[5,7]$. The optical satellite data have numerous merits like 
true color images through which visual interpretation and automatic classification can be done to provide first-hand information of the flooded areas. High-resolution visible/ infrared sensors allow the extraction of the flooded areas. Near infrared imageries are particularly efficient since the near infrared spectral bands are robustly absorbed by water, yet reflected by land. Giordan et al. [8] have presented a methodology of mapping and quantifying flood impacts in urban and cultivated areas using multisensor data, interested in free or low-cost data/sensors. Very high-resolution images like QuickBird, WorldView-2, and Ikonos can supply more precious information than those like Landsat and ENVISAT. However, they have some disadvantages such as the expensive price and long revisit time that consequently still limit their applications in urban flood impact monitoring.

Spaceborne radar is the active sensor which emits a radar pulse and records the land surface backscatter at the satellites. It has some merits over optical satellites; not only the ability of data collection through cloud cover and during the night $[9,10]$ but also it has the ability of continuous observation of flood events for accurate, rapid, and costeffective flood mapping. Both optical and SAR satellite remote sensing data have an effective capacity to monitor and assess the flood impacts in vegetation area. In contrast, some drawbacks in the urban area represent insufficiency to observe flood impacts because of the following reasons: (1) temporal resolution is limited and (2) satellites (ENVISAT, ASAR, and Landsat) unable to capture the details of the urban area because of lower spatial resolution. With the launch of Sentinel-2 satellite, it allowed the great chance to assess the flood influence in the urban area. The merits of Sentinel-2 can be summarized in (1) high spatial resolution $(10 \mathrm{~m})$ for the visible bands, (2) having 13 multispectral bands, and (3) just five days to cover the whole Earth.

Aerial remote sensing technology has abundant merits such as low flight altitude, which is not affected by clouds and, furthermore, the very high spatial resolution (decimeter levels) which allows monitoring and assessment of flood impacts in the complex urban area compared with spaceborne observations. However, it requires more time to process in addition to the limited coverage area and governmental permission as well.

With the rapid advance of remote sensing techniques, an unmanned aerial vehicle (UAV) system was introduced which is able to capture ultrahigh spatial resolution images. However, the main disadvantage of UAV in urban flood mapping is the finding of taking-off and landing places especially for fixed-wing airplanes. Furthermore, it needs governmental permission in many Countries and just limited coverage. Feng et al. [11] deal with modern remote sensing technology through the UAV system which can provide ultrahigh-resolution data with a great potential for accurate detection of inundated areas under complex urban landscapes. The results demonstrated that UAV gives satisfying performance in urban flood monitoring application.

Traditional surveying techniques such as GPS and total station accurately contribute to survey flooded impacts in the urban area. However, these techniques need more and more time and work in the difficult environment. So, Rimba et al. [12] employed modern remote sensing data, GIS, and AHP to localize the physical flood-vulnerable area in the Okazaki city. The map generated by applying analytical hierarchy process (AHP) is coincident with flood inundation survey of the city on August 2008.

The commonly utilized methods to delineate flooded region include thresholding, change detection, spectral indices (MNDWI and NDWI), and decision trees [7, 13, 14]. The visual interpretation is the important and effective technique for flood impacts realization owing to the presence of misclassification in case of using automatic unsupervised classifications of flooded areas. In this work, we adopted maximum likelihood supervised classification technique to classify pre- and post-flash flood images. It is an efficient method to classify objects in addition to being a statistical method where its results include both the category which a pixel belongs to and its membership probability as well. Then, change detection is applied to assess flood impacts. We carefully selected the training samples accurately based on visual interpretation and images from the site.

The current study focuses on October 28, 2016, flood disaster in Ras Gharib city. The overall objectives of this study are as follows. (1) The flash flood impacts on Ras Gharib city are monitored based on free satellite data (Sentinel-2) and mapping the destroyed areas. (2) Fuzzy analytical hierarchy process (FAHP) method and a geographical information system (GIS) are integrated for flood risk analysis and evaluation in the flood-prone area. (3) Such a flood vulnerability map is used as an index to assist the decision-makers prepare for probable flooding.

\section{Description of Study Area}

The city of Ras Gharib was established in 1938. Geographically located at $33^{\circ} 4^{\prime} 59.66^{\prime \prime} \mathrm{E}$ and $28^{\circ} 21^{\prime} 34.92^{\prime \prime} \mathrm{N}$ with approximately $10,464.46 \mathrm{~km}^{2}$. Number of inhabitants that dwell in the city is about 60000 . The terrain elevation varies from $4 \mathrm{~m}$ up to $750 \mathrm{~m}$ above M.S.L. Generally, the study area has a semiarid climate. The average annual temperature is $22.2^{\circ} \mathrm{C}$. During the year, there is virtually no rainfall so no flash flood has occurred. However, with the global climate change, the rainfall has started. Figure 1 focuses on the location of Ras Ghareb which has recently exposed to flash floods. When the rainfall flowed inside the study area passing through Wadi Eldarb catchment area, it caused the destruction of the city infrastructure. The quantity of water which struck the city is calculated about 130 million $\mathrm{m}^{3}$ as mentioned in the municipal government report. The water level in the city reached 1.5 to $2 \mathrm{~m}$ high with a speed of $22 \mathrm{~km} / \mathrm{h}$. Figure 2 displays the outlet of Wadi Eldarb catchment which influences the mentioned city. Table 1 shows the properties of the Wadi Eldarb catchment. The city comprises various land use activities in addition to the production of $65 \%$ of Egypt requirements of petroleum. Furthermore, it is considered as a tourist city where tourism is flourishing there greatly. The geometric path of Ras Ghareb-Minya Road caused in transferring a massive quantity of water to the city. The part of the highway, which 


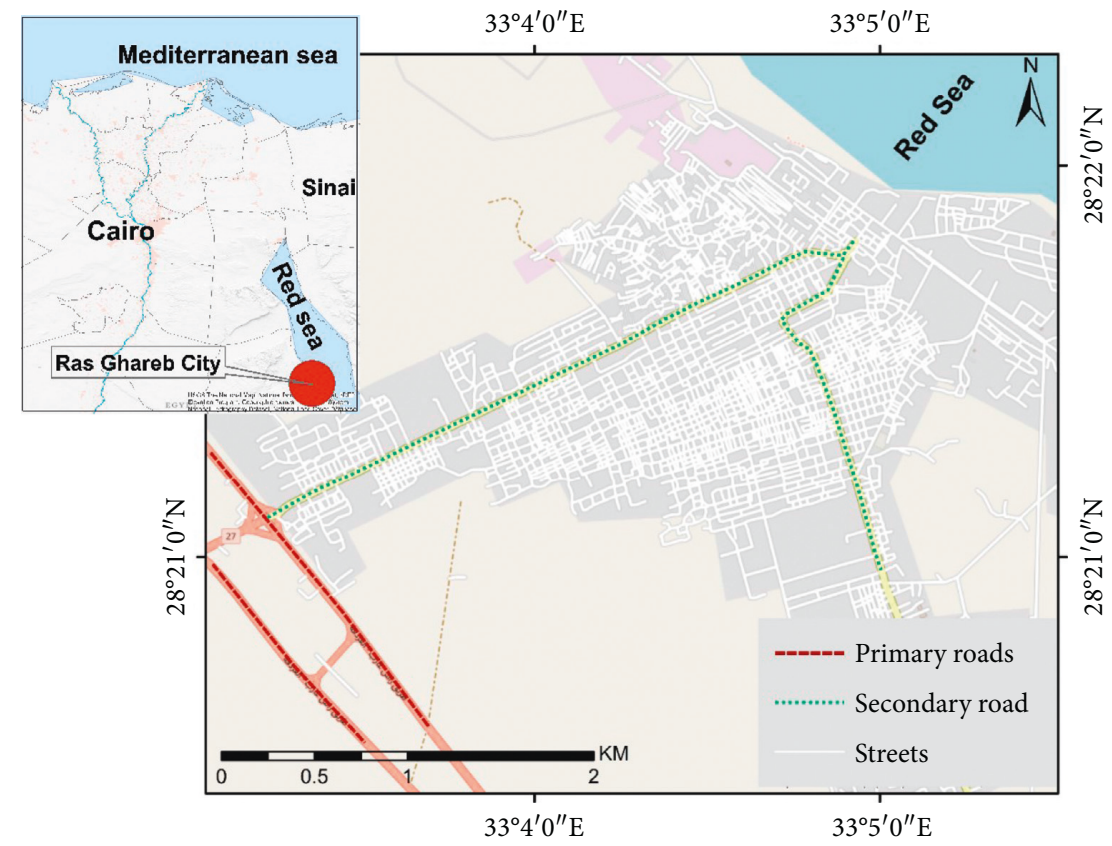

Figure 1: The location of the study area of Ras Ghareb City.

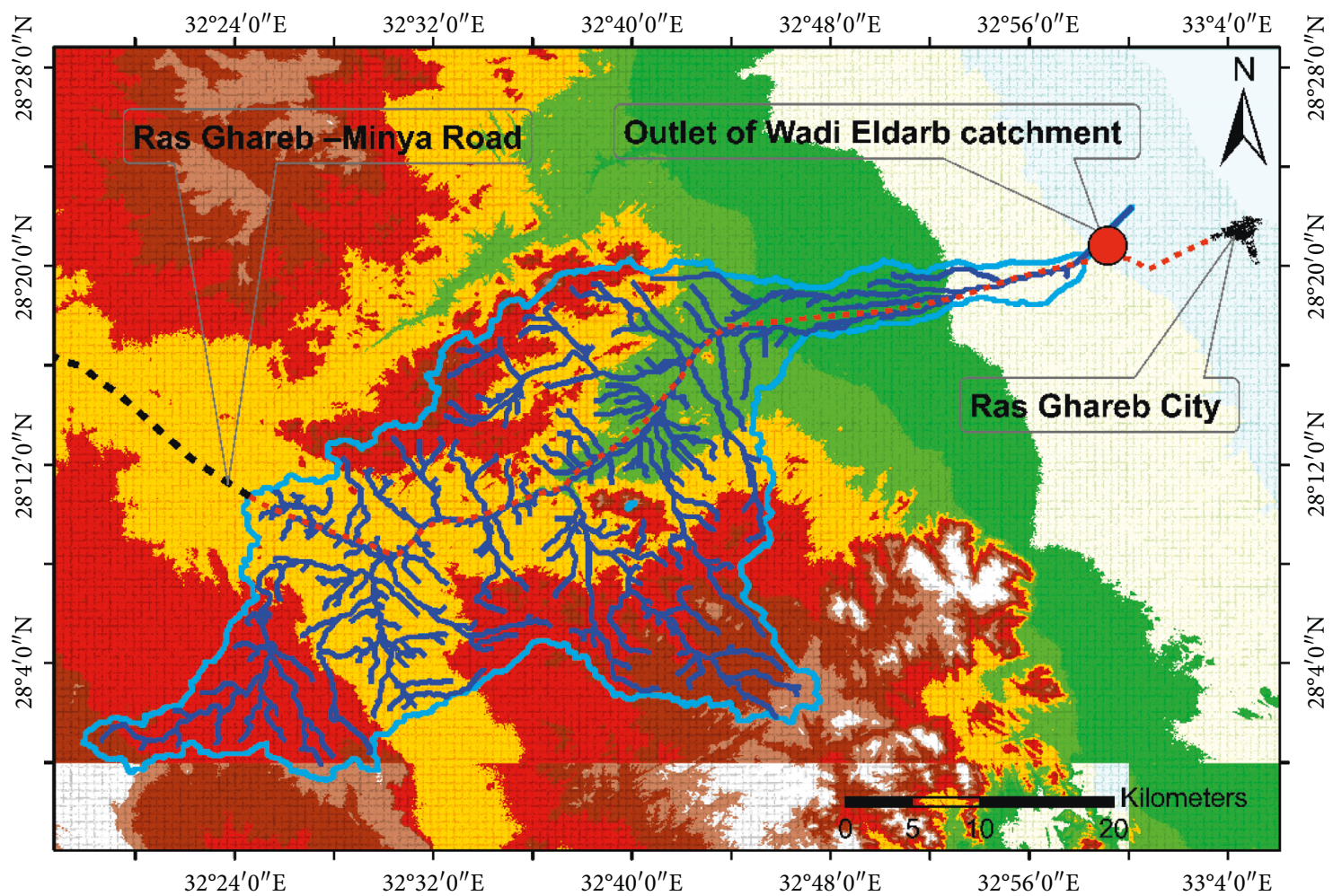

DEM

elevation

\begin{tabular}{|c|c|c|c|}
\hline$-7-120$ & $680-770$ & --- & Improper part of the road \\
\hline $130-280$ & $780-880$ & --- & Road \\
\hline $290-420$ & $890-1000$ & - & Stream network \\
\hline $430-560$ & $1100-1200$ & & Study area \\
\hline $570-670$ & $1300-1700$ & & Catchment \\
\hline
\end{tabular}

FIGURE 2: Wadi Eldarb catchment area which directly influences Ras Ghareb city. The geometric path of Ras Ghareb-Minya Road caused in transferring massive quantity of water to Ras Ghareb city presented in red line. 
TABle 1: Properties of Wadi Eldarb catchment.

\begin{tabular}{lcccccc}
\hline Properties & $\begin{array}{c}\text { Area } \\
\left(\mathrm{km}^{2}\right)\end{array}$ & $\begin{array}{c}\text { Perimeter } \\
(\mathrm{km})\end{array}$ & $\begin{array}{c}\text { Length } \\
(\mathrm{km})\end{array}$ & $\begin{array}{c}\text { Basin } \\
\text { slope }\end{array}$ & Mean Basin elevation (m) & Maximum flow distance (km) \\
\hline Wadi Eldarb catchment & 1049 & 305.2 & 79.8 & 0.06 & 635.5 & 103.2 \\
\hline
\end{tabular}

has an improper drainage system, is highlighted as red. As the road is paved, it lacks the infiltration and increases the runoff speed. Consequently, this part of the road became a carrier to the runoff helps it to be sharper. From the beginning, the design of the city focused on zone A. Because no destructive flash food over a 70 year period has occurred until the flash flood of 2016 was $51.3 \mathrm{~mm}$, the urbanization has expanded over zones $\mathrm{B}$ and $\mathrm{C}$ over the years as was believed, no worries about these areas (Figure 3). Thus, no drainage system has been established before. Just recently, the local government is seeking hard to implement protective actions.

\section{Data Set}

3.1. Sentinel-2 Images. The choice of the most convenient satellite data depends on many factors: (i) characteristics of the study area, (ii) spatial resolution, (iii) revisit time, (iv) time of acquisitions with respect to the moment of maximum inundation, and (v) availability and cost of images [8]. According to these conditions, Sentinel-2 provides really practical satellite data to validate urban flash flood impacts.

Sentinel-2 satellite was launched in 2015 by European Space Agency (ESA) which has abundant merits. For instance, fast revisit time (5 days with two satellites), global coverage with a wide field of view $(290 \mathrm{~km})$, and high resolutions $(10 \mathrm{~m}, 20 \mathrm{~m}$, and $60 \mathrm{~m})$. The major objective of the Sentinel-2 mission is to provide high-resolution optical imagery for the operational land cover maps and land change detection maps [15].

Sentinel-2 data consist of 13 spectral bands in the VNIR and SWIR domains with spatial resolutions ranging from 10 to $60 \mathrm{~m}$. VNIR consists of 4 bands (blue, green, red, and near infrared) with $10 \mathrm{~m}$ spatial resolution, while SWIR includes 6 bands ( 4 narrow SWIR bands and 2 wider SWIR bands) with $20 \mathrm{~m}$ spatial resolution, in addition to 3 bands of $60 \mathrm{~m}$ spatial resolution for atmospheric correction application [15].

The Sentinel-2 L1C products are geometrically corrected with respect to the Universal Transverse Mercator map projection (UTM-WGS 84). Sentinel-2 images are available through the USGS Earth Explorer web browser. The employed images for this study were captured on October 13, 2016, and November 2, 2016, when the flash flood occurred on October 28, 2016. Sentinel-2 images were processed based on Sen2Cor software to produce Sentinel-2 Level-2A. Figure 3 demonstrates pre- and post-flash flood images. Based on visual interpretation of Sentinel-2 images, the study area was divided into three zones $\mathrm{A}, \mathrm{B}$, and $\mathrm{C}$.

3.2. SRTM One Arc Second. The Shuttle Radar Topography Mission (SRTM) was launched on February 11-22, 2000, by aboard the Space Shuttle Endeavor. The National

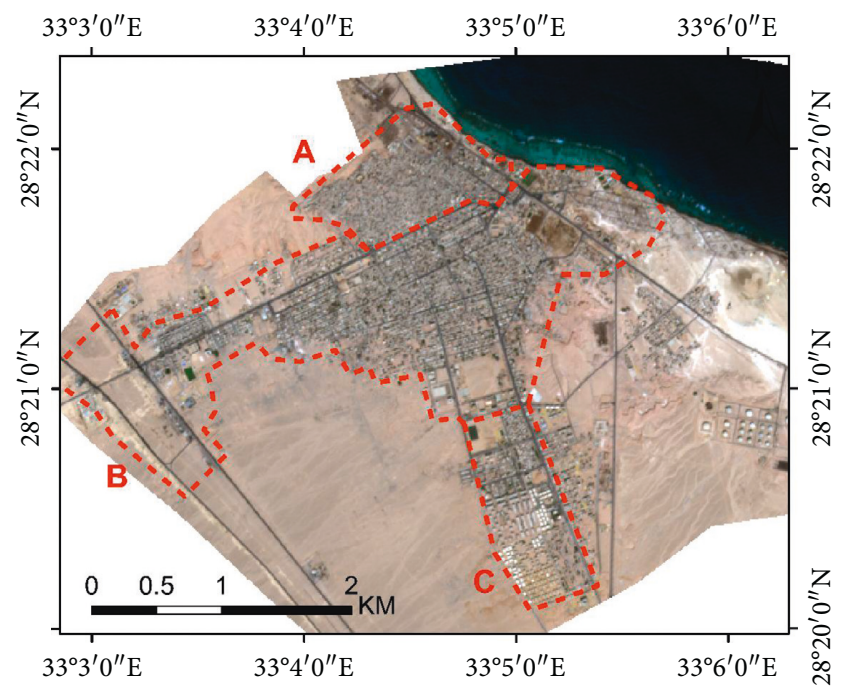

(a)

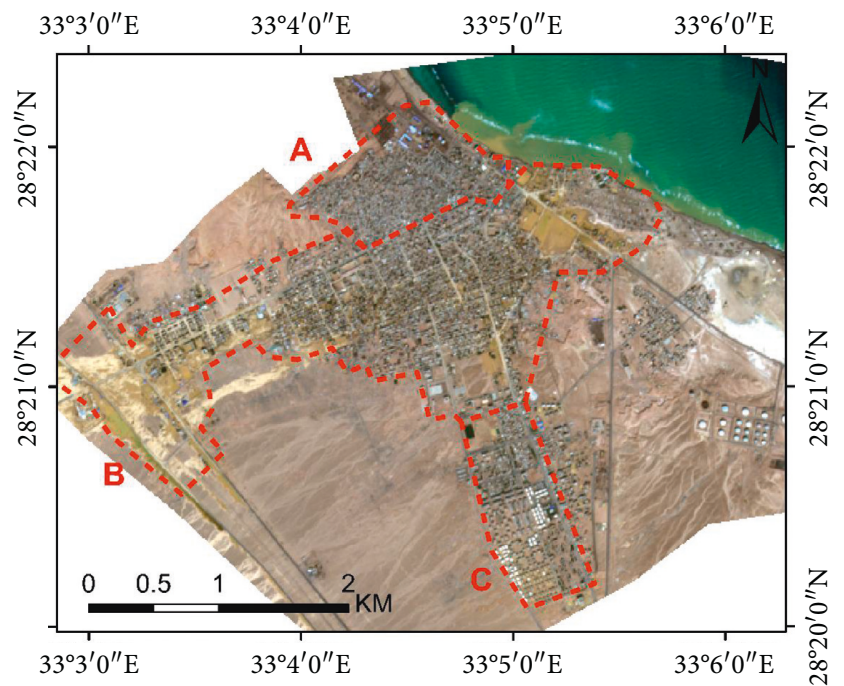

(b)

Figure 3: The study area: (a) before flash flood and (b) after flash flood.

Aeronautics and Space Administration (NASA) and the National Geospatial-Intelligence Agency (NGA) contributed in an international project to create the first nearglobal set of land elevations. SRTM data are successfully collected over $80 \%$ of the Earth's land surface between $60^{\circ}$ $\mathrm{N}$ and $56^{\circ} \mathrm{S}$ latitude. It has three spatial resolution outputs available, including $1 \mathrm{~km}, 90 \mathrm{~m}$, and $30 \mathrm{~m}$ resolution. SRTM DEM data are referenced horizontally to WGS84 ellipsoid and vertically to EGM96 geoid orthometric heights [16]. SRTM data vertical accuracy is less than or equal to \pm 7 meters [17], while horizontally is about \pm 20 meters [18]. The SRTM elevation data for the study area were 
downloaded from http://earthexplorer.usgs.gov website. The SRTM version 3 was utilized for this study instead of the previous version (version 1 and version 2.1). It has been developed and then released after using the sophisticated interpolation and hole filling algorithms which allow the use of ancillary data sources when they are available [19]. SRTM, 1 arc-second spatial resolution, was used to produce the slope map and streams networks.

3.3. Social Media and Internet Webpages. All available data like geolocated photos or derived information provided by social media and the Internet $[20,21]$ or by volunteers $[22,23]$ can be very beneficial to improve the mapping of the flooded areas. Therefore, we have searched in the Internet webpages, and we have found precious images, images captured by using a helicopter and terrestrial images by a geographic information volunteer. These images significantly contribute to determine the area inundated and preknowledge of the classification results.

The helicopter images greatly contributed to understanding flood propagation. Visual interpretation confirmed that the three zones have been affected. According to the area and the distribution of risk levels, B is the most influenced one. Figure 4 shows the areas covered by the helicopter images after B. Figures 5(a) and 6(a) represent the the helicopter images captured on October 28, 2016, after the lood from where damage information was extracted and then were overlaid on Google Earth images. Based on visual interpretation, the main roads like Zahfarana-Ras Ghareb and Hurgada-Al Ismaileya roads were exposed to the destruction. Furthermore, the floodwater is spread causing difficulty in providing aid. In addition, it is noted that the pavement layer is changed to the sandy layer. Moreover, the water bodies settled in most of zone B streets such as El Malek Soud Street. The ephemeral water bodies settled in the lower area of zone B as a result, the water clearly appeared in main and substreets.

Figures 5(b) and 6(b) are Google Earth images whose high resolution is convenient to cooperate with the helicopter images for precise determination of the destroyed area. In contrast, the Sentinel-2 image is not suitable because the features do not clearly appear. The Google images help classify streets which have complete or partial paving layer that supports the decision-maker to estimate the initial cost of the street network damage.

\section{Methodology}

The destroyed area and the water bodies are determined utilizing two Sentinel-2 scenes. The maximum likelihood supervised classification method is used in image classification. The fuzzy analytic hierarchy process (FAHP) method is applied for flood vulnerability mapping. Finally, flood vulnerability map produced by FAHP will be validated based on change detection between the two Sentinel2 images. Figure 7 shows the conceptual methodology applied to estimate the flash flood impacts and achieve the other objectives.

\subsection{Determination of the Destroyed Area}

4.1.1. Land Use and Land Cover Change (LUCC). Both normalized difference water index (NDWI) and modified normalized difference water index (MNDWI) (Xu_2006) were applied to delineate water bodies; however, the results were not satisfying because the postimage was captured few days after the flash flood. Subsequently, the maximum likelihood supervised classification technique is employed to classify Sentinel-2 images after and before the flash flood using ArcGIS 10.2 software.

The substantial objective of image classification is determining the destroyed areas and the ephemeral water bodies. Two dated Sentinel-2 images were compared according to consequences of maximum likelihood supervised classification. The training samples desired for each class in addition to those for classification accuracy assessment are gained based on Google Earth Pro.

Classification accuracy is an extremely important step to ensure precise change detection results. Google Earth Pro has an avail to validate the accuracy of the classified images. The checkpoints for evaluating the classified images are selected with proportionality between the sample numbers and location in a category and the type and the size of that category, to obtain higher classification accuracy [25]. Accuracy assessment is expressed by overall accuracy and kappa statistic which were derived from the error matrix [26]. After the change detection between the classified images, the destroyed infrastructure is highlighted.

4.1.2. Fuzzy Analytical Hierarchy Process. The analytical hierarchy process (AHP) is a technique of multicriteria decision analysis (MCDA), implemented by GIS, which defines the weights of the criteria selected [27, 28]. The AHP tool helps in decision-making and solving complex problems, which was carried out and developed by Saaty [29]. Despite popularity of AHP, this method is often criticized for inability to sufficiently control the immanent uncertainty associated with the mapping of the decisionmaker's grasp to exact numbers [30]. Owing to the ignoring of uncertainity in traditional AHP, FAHP (the fuzzy extent analysis) is preferable when complex multiattribute decision-making problems are considered. The FAHP method is employed in this research for flood vulnerability mapping. Five different maps (slope map, streams network, soil map, roughness surface, and cover type layers) were generated from the following three data sources: DEM, Sentinel-2 images, and soil map. The next step was to assign weight and rank values to the layers and the classes of each layer, respectively. The assignment of the weight/rank values and their analysis were realized by the FAHP method. Previous studies used many parameters for applying the FAHP method such as soil map, slope map, drainage map, and curve number. The degree of impression of those different parameters is unequal; some parameters are dominant over others. The weight of each parameter depends on the level of susceptibility [31]. A committee of 16 experts (four hydrologists, four engineers, and eight 


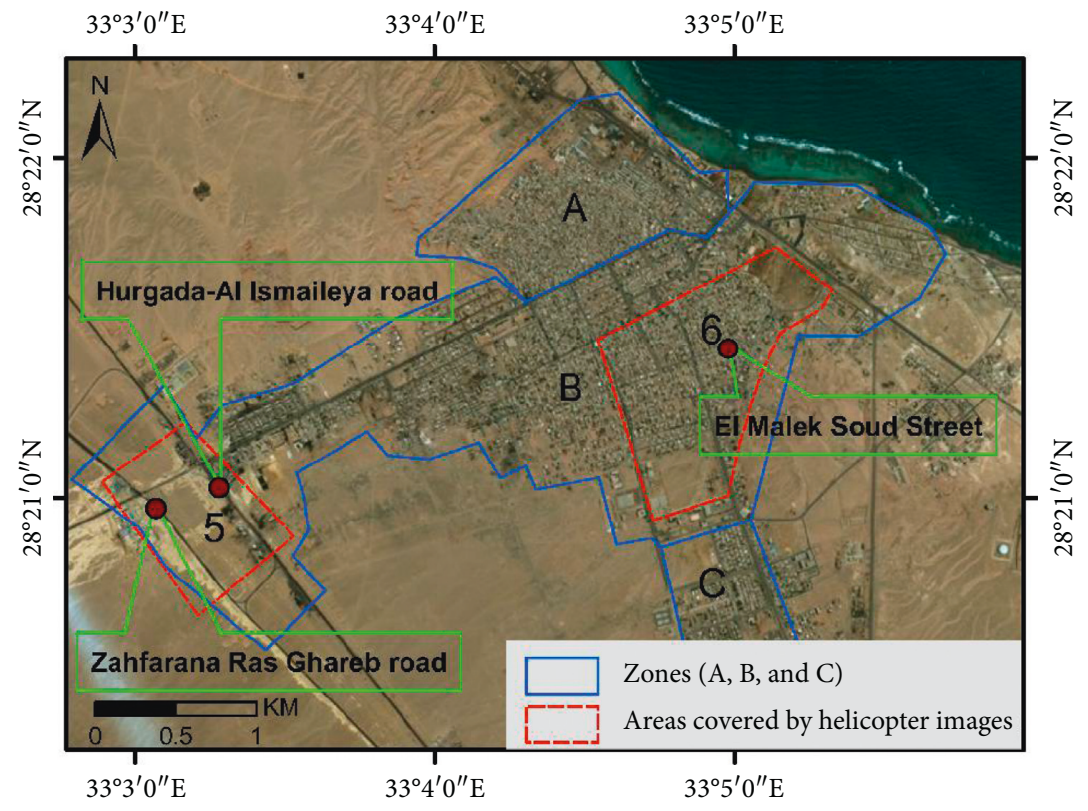

FIGURE 4: The streets through the study area in addition to the areas covered by the helicopter images after the flash flood.

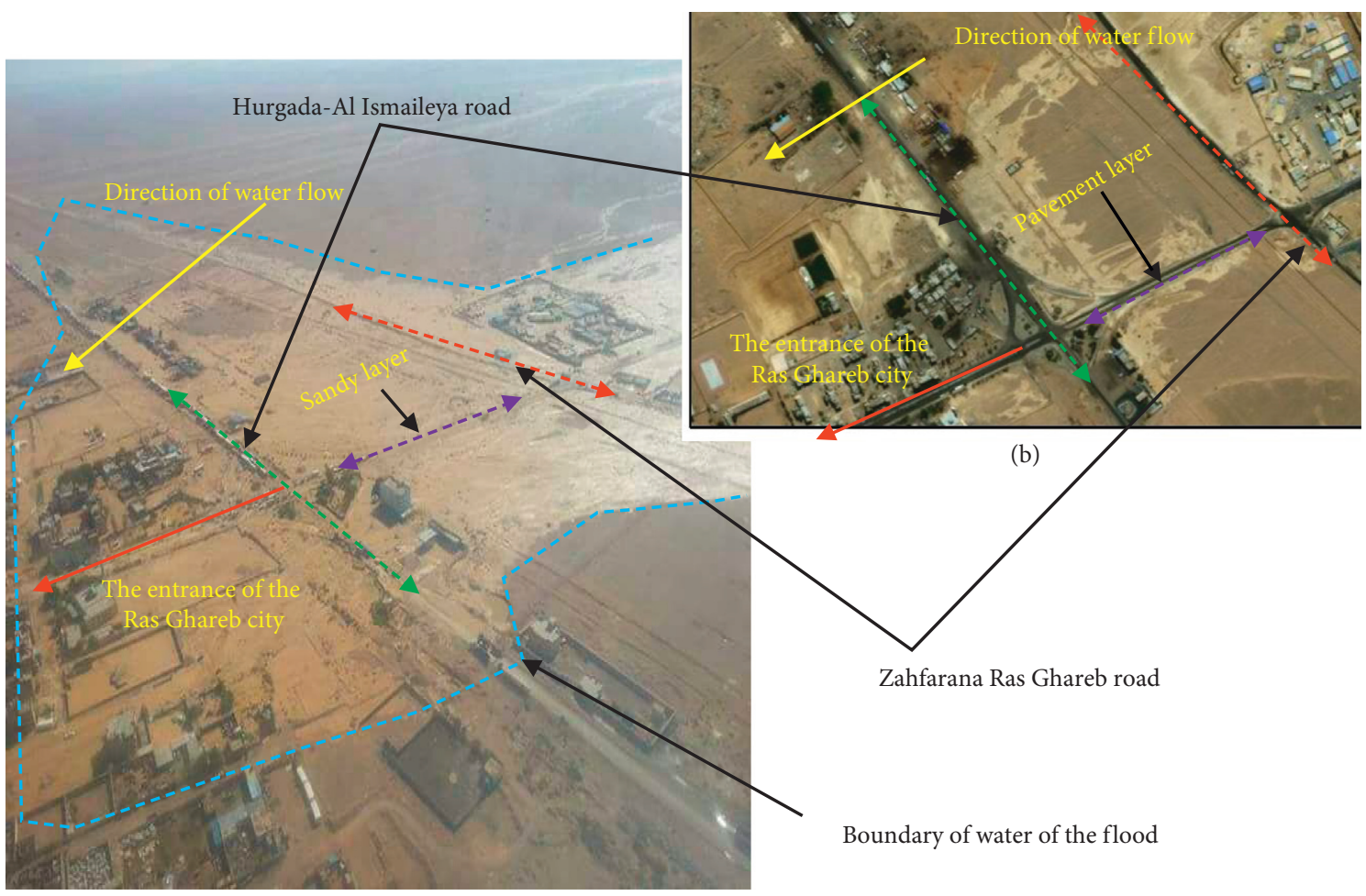

(a)

FIGURE 5: (a) A helicopter image captured on 28/10/2016 aerial view of the flooded area found on the webpage https://www.almasryalyoum. com/news/details/1031509. (b) The damage information extracted from the helicopter image which overlaid Google Earth images.

end-users) determined the most effective parameters. They validate six high-influence parameters represented in rainfall, drainage density, elevation, slope, soil, and land use [12]. Actually, only five physical criteria were enough to use in this research, which involve land cover, slope, stream channels, soil, and surface roughness. The fuzzified pairwise comparison matrices (FPCMs), which are triangular fuzzy comparison matrices (equation (1)), are carried out by comparing all the possible pairs of criteria in order to determine which of all those criteria has a higher 


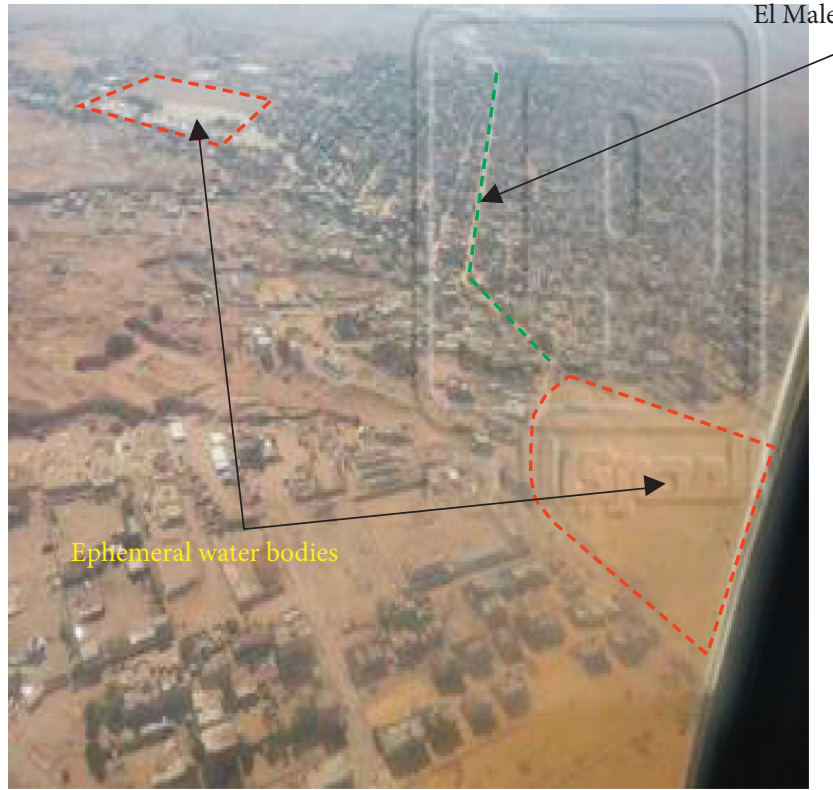

(a)

(b)

Figure 6: (a) The ephemeral water bodies settled in the lowest area of zone B, and then, the water clearly appeared in the main and substreets. (b) The Google image helps classify streets of complete or partial paving layer.

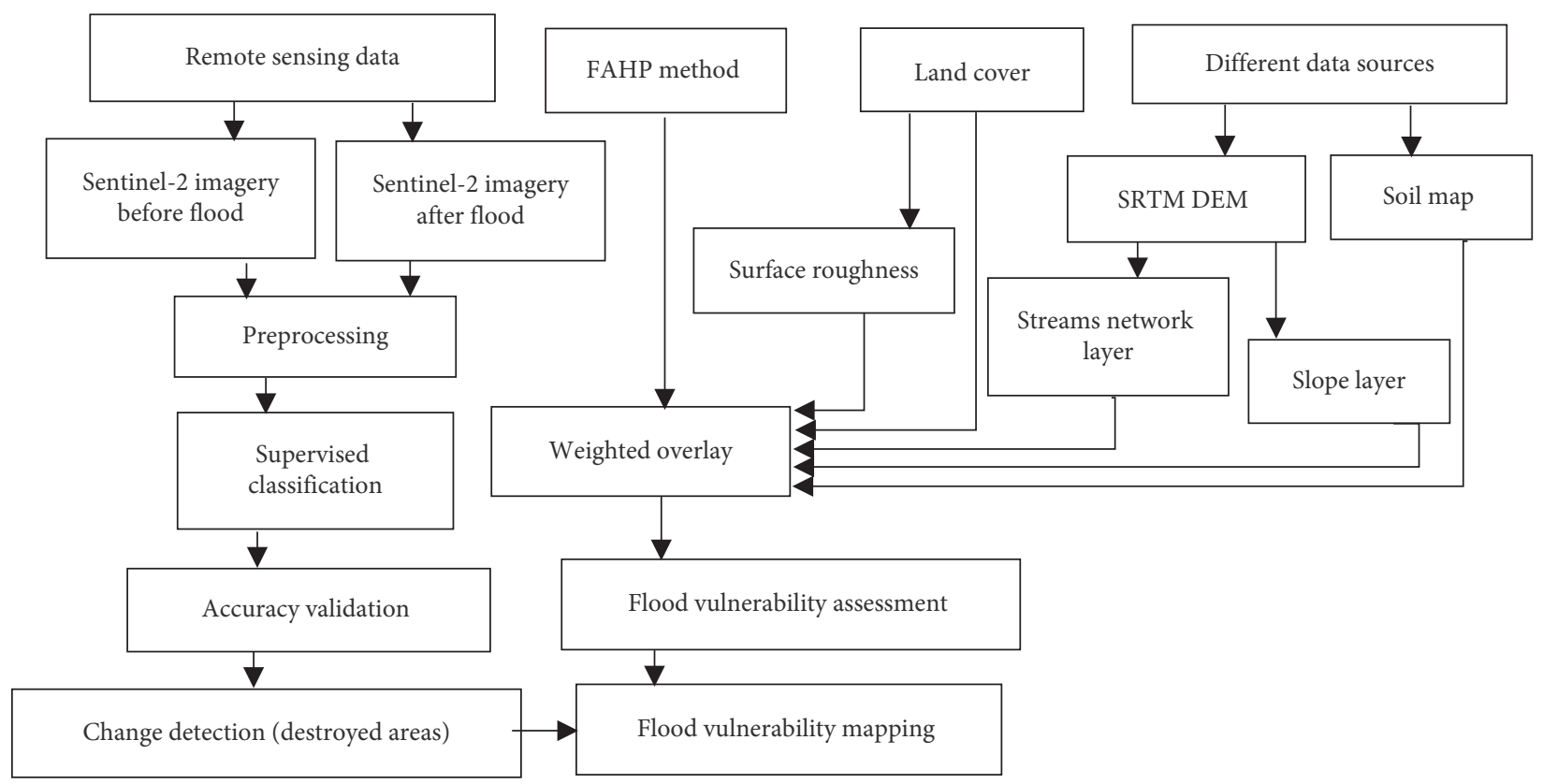

FIGURE 7: The conceptual methodology.

priority. Every element takes a value from 1 to 9 (Table 2) according to its importance where the value 1 indicates that the criteria are equally important and a value of 9 indicates that the criterion under consideration is extremely important compared to the other criteria. This is called scaling. FAHP is done by applying eight steps considered as follows:

(1) Formation of the fuzzified pairwise comparison matrix as indicated in the following:

$$
\widetilde{\mathbf{A}}=(\widetilde{\mathbf{a}})_{\mathbf{n} * \mathbf{n}}=\left[\begin{array}{cccc}
(1,1,1) & \left(l_{12}, m_{12}, u_{12}\right) & \ldots & \left(l_{1 n}, m_{1 n}, u_{1 n}\right) \\
\left(l_{21}, m_{21}, u_{21}\right) & (1,1,1) & \ldots & \left(l_{2 n}, m_{2 n}, u_{2 n}\right) \\
\ldots & \ldots & \ldots & \ldots \\
\left(l_{n 1}, m_{n 1}, u_{n 1}\right) & \left(l_{n 2}, m_{n 2}, u_{n 2}\right) & \ldots & (1,1,1)
\end{array}\right]
$$

(2) Calculation of the fuzzy synthetic extent with respect to $i^{\text {th }}$ alternative as follows: 
TABle 2: Average random consistency indices (RI) for different number of criteria (adapted from [32]).

\begin{tabular}{lcccccc}
\hline Number of criteria $(N)$ & 1 & 2 & 3 & 4 & 5 & 6 \\
\hline Random consistency indices (RI) & 0 & 0.0 & 0.58 & 0.90 & 1.12 & 1.24 \\
\hline
\end{tabular}

$$
s_{i}=\sum_{j=1}^{n} a_{i j}\left|\sum_{i=1}^{n} \sum_{j=1}^{n} a_{i j}\right|^{-1},
$$

where $a_{i j}$ is the element of the FPCM of $n$ : no. of criteria.

(3) Calculation of the degree of possibility for a convex fuzzy number to be greater than each other fuzzy number (the following equation) and $k$ convex fuzzy numbers:

$$
\begin{aligned}
V\left(s_{1 \geq} s_{2}\right) & =\sup _{y \geq x}\left\lfloor\min \left(\mu_{s_{1(x)}}, \mu_{s_{2(x)}}\right)\right\rfloor=\operatorname{hgt}\left(s_{1} \cap s_{2}\right), \\
& = \begin{cases}1, & \text { if } m_{1} \geq m_{2}, \\
0, & \text { if } l_{2} \geq u_{1}, \\
\frac{l_{2}-u_{2}}{\left(m_{1}-u_{1}\right)-\left(m_{2}-l_{2}\right)}, & \text { otherwise. }\end{cases}
\end{aligned}
$$

(4) Calculation of the weight vector and normalize the nonfuzzy weight vector.

(5) Computing $\lambda_{\max }$ (the principal eigenvalue).

(6) Estimating the consistency index (CI) that measures the inconsistencies of pairwise comparisons can be expressed by the following equation:

$$
\text { C.I. }=\frac{\lambda_{\max }-n}{n-1},
$$

where $n$ is the number of criteria and $\lambda_{\max }$ is the highest eigenvalue $[28,33]$.

(7) Determining the appropriate value of the random consistency ratio (RI) (Table 2).

(8) Calculating CR, which is computed using the following formula (5):

$$
\mathrm{CR}=\frac{\mathrm{CI}}{\mathrm{RI}}
$$

4.1.3. Flood Vulnerability Variable. The selection of criteria is significantly vital and profound step in the multicriteria decision analysis. Major criteria causing flood in the study area can be concluded as land cover (LC), stream channels (SC), slope (SL), soil (SO), and surface roughness (SR).

SRTM has been already used to extract the slope map. The general direction of the runoff in the study area is westeast and slopes vary from more than 15\% along the western border to less than $1 \%$ in the eastern part of the area. The values were subdivided into six classes. A multibuffer operation is applied to stream channels to determine all the areas within the specified distance of the channels. The distance intervals applied were $<1000 \mathrm{~m}, 1000$ to $2000 \mathrm{~m}$, 2000 to $3000 \mathrm{~m}$, and 3000 to $4000 \mathrm{~m}$. Hydrology tools are useful for extracting the stream network based on SRTM. Land cover is the result of the classification process of Sentinel-2 images. Values of surface roughness are classified from 0.03 to 0.1 according to land use type. The soil map of the study area was classified into three main categories: fine sand, sandy clay, and coarse sand.

\section{Results and Discussion}

5.1. Analysis of LUCC. In this study, totally, six LULC classes were specified as sea water, bare soil, buildings, roads, desert, and quarry area. The classification results of the pre- and post-flash flood images are illustrated in Figure 8. The flash flood has caused massive damage to infrastructure. Before the flash flood, the areas of roads, buildings, quarry area, sea water, desert, and bare soil have been 334.4, 403.8, 42.6, $824.2,1024$, and 31.1 hectares, respectively, while after the flash flood, areas have become 215.8, 302.2, 12.4, 825.1, and 1271.2 ha. Accordingly, water bodies were created covering 33.4 ha. With respect to the previous results, it is clear that the areas of roads, buildings, and quarry area have reduced because of the catastrophic flash flood. For bare soil, it has exchanged with water bodies which gathered in the depressed areas. On the contrary, desert area has increased on account of the roads as the flash flood left a layer of sand sediment on the pavement. Figure 9 explicates a representation of the area of each category before and after the flash flood (notice the change). The overall accuracy and kappa coefficients of the pre- and post-flash flood classified images are $90.83 \%, 0.86$ and $89.16 \%, 0.85$ respectively.

As a result of the change detection analysis, the destroyed areas (road network and water bodies) are clearly concentrated in zone $\mathrm{B}$ owing to being the lowest area in the city while area $\mathrm{C}$ is less affected as it is the highest. Also, zone A suffered from damage as shown in Figure 10. The destroyed area extracted from the change detection is coincident with the results of visual interpretation of the helicopter images. In other words, Sentinel-2 satellite images prove high efficiency to assess the damage in the main and secondary road networks and detect ephemeral water bodies inside cities; however, the estimation of the destroyed buildings is complex.

5.2. FAHP Analysis. The results of the questionnaire are concluded in Table 3, and the authors' opinions were chosen according to the scale 1-9, and then the fuzzified pairwise comparison method (FPCM) was applied within the FAHP to check the CR and to identify the final weights for each criterion. The results of the FPCM (weights, $\lambda_{\text {max }}$, CI, RI, and $\mathrm{CR}$ ) are summarized in Table 4. Each layer is divided into subclasses, for example, slope layer split into six classes near level, very gentle slope, gentle slope, moderate slope, 


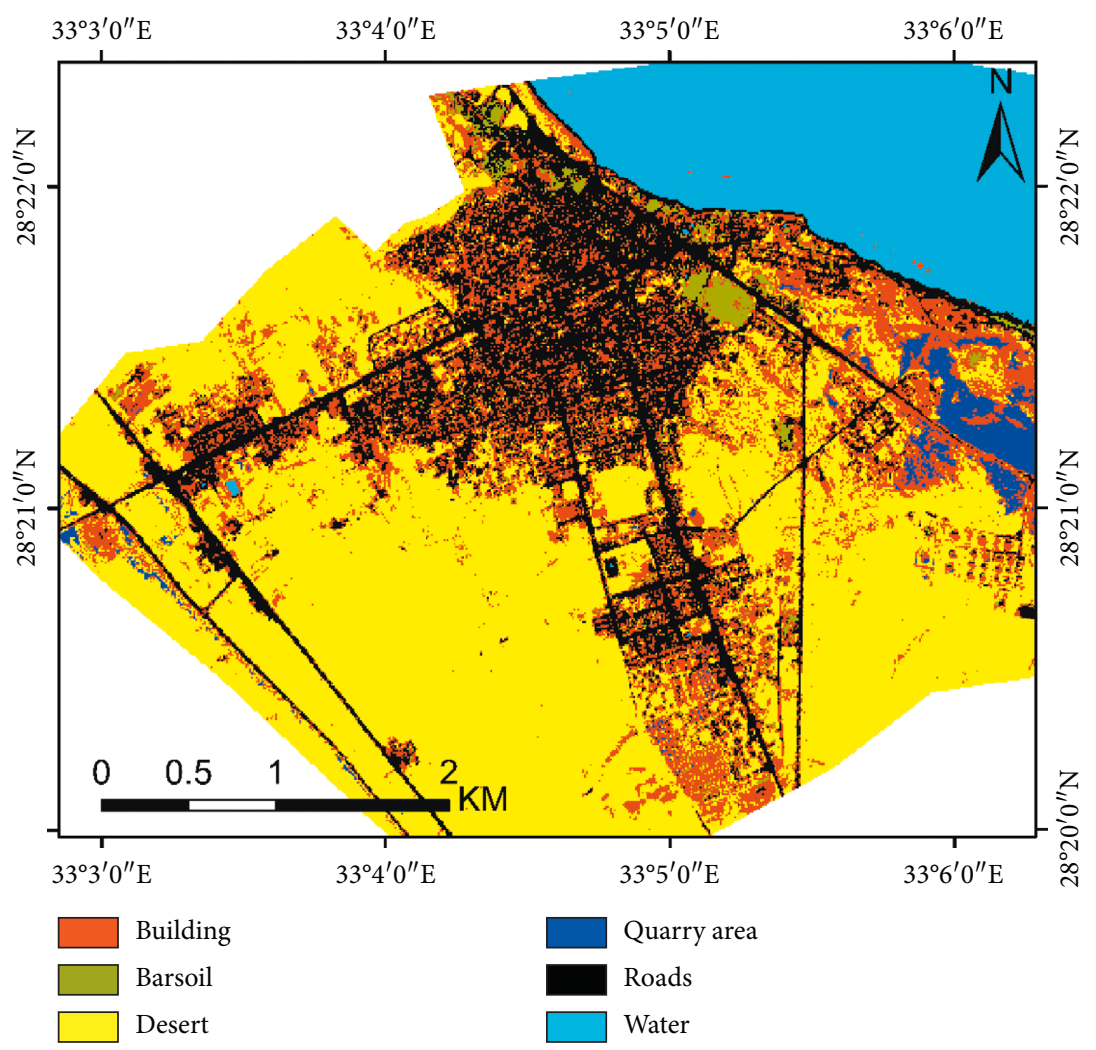

(a)

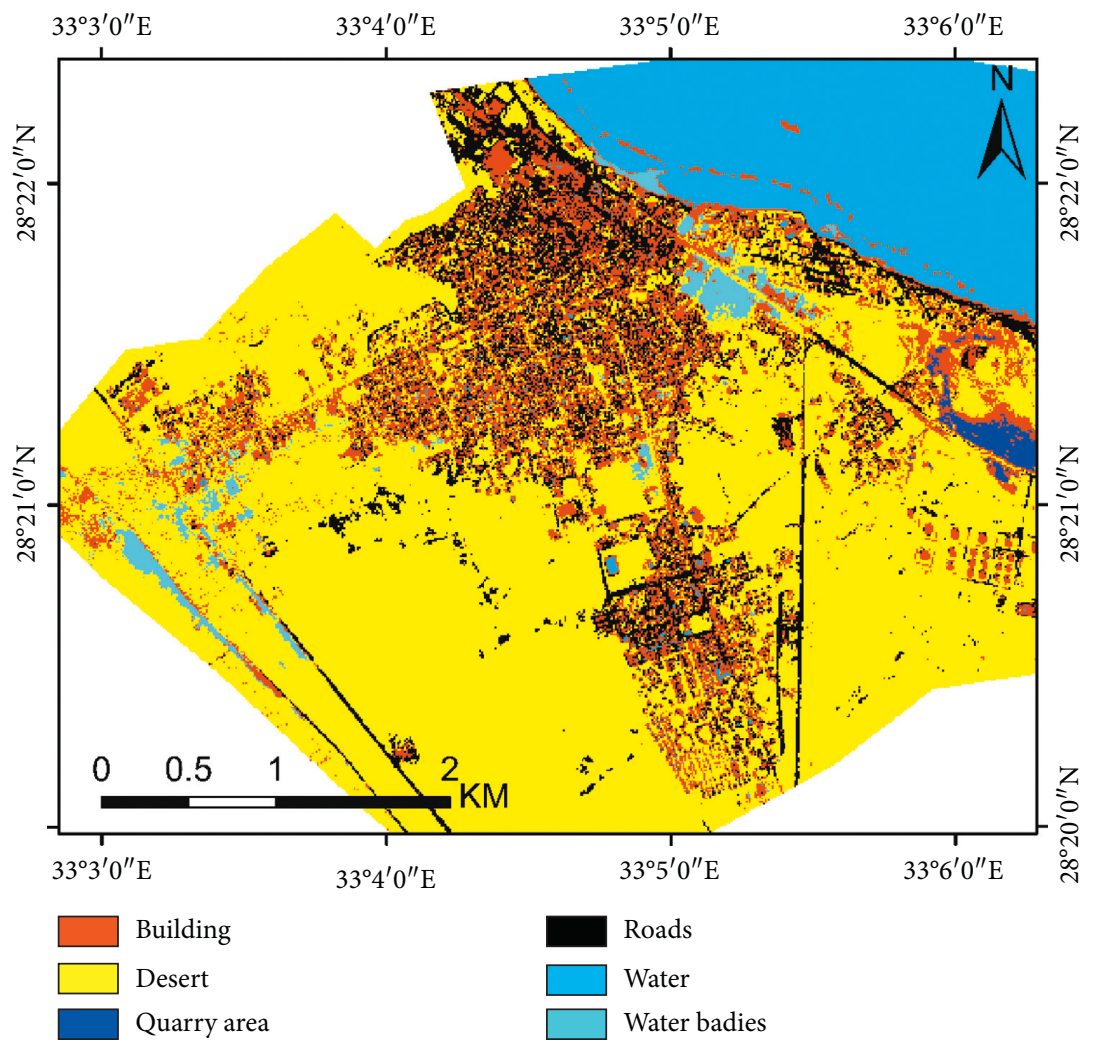

(b)

FIgURe 8: The classified images: (a) before flash flood and (b) after flash flood. 


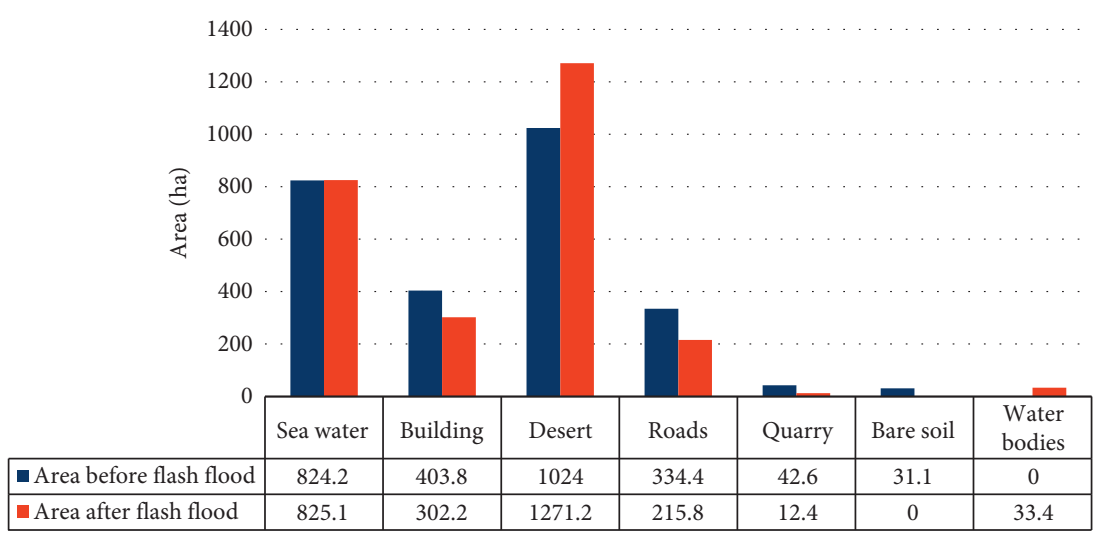

Figure 9: The destroyed area of each category in hectare (ha).

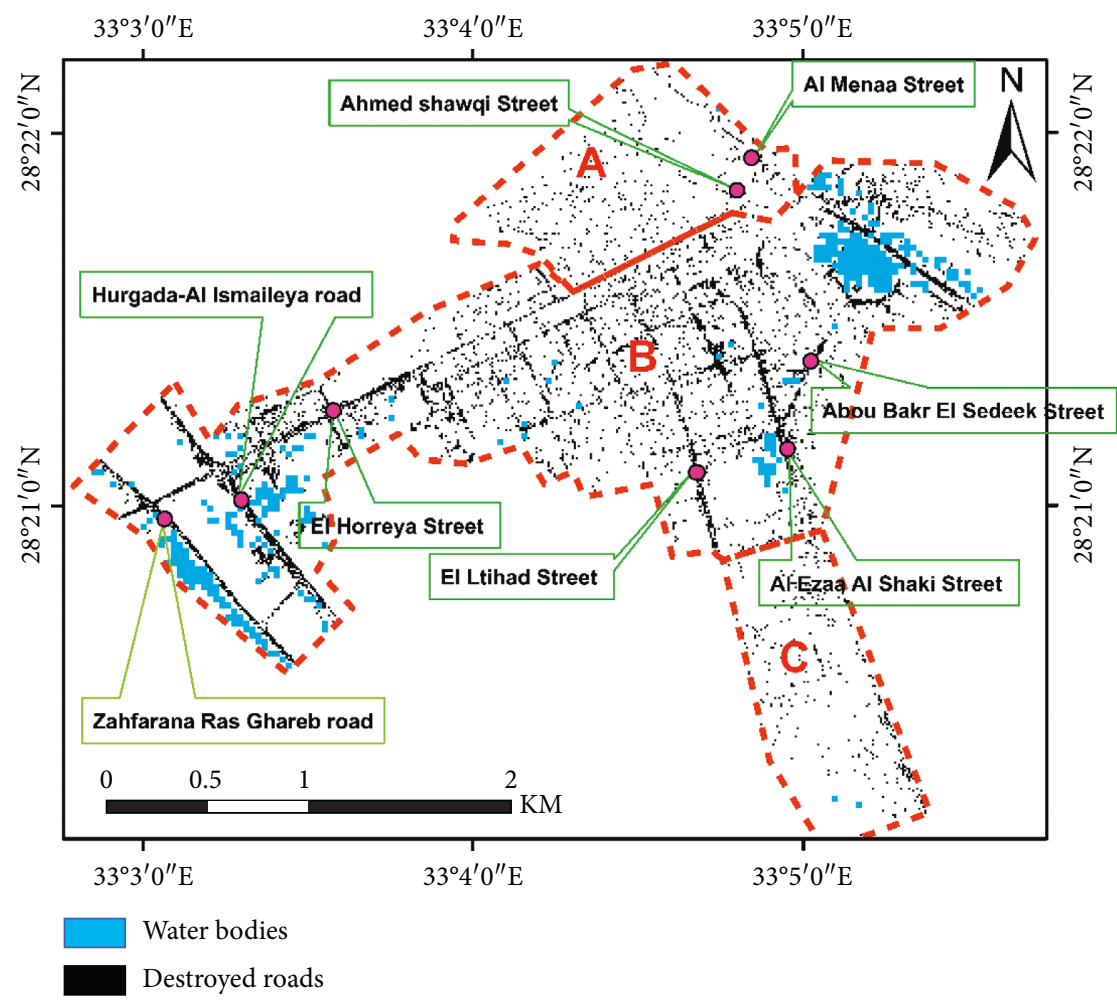

FIgURE 10: The damage of the main and branch road network, also the location of the ephemeral water bodies inside the city.

TABle 3: The pairwise comparison matrix of authors' opinions.

\begin{tabular}{lccccc}
\hline Criteria & Land cover & Slope & Surface roughness & Soil & Stream channel \\
\hline Land cover & $(1,1,1)$ & $(1,2,3)$ & $(2,3,4)$ & $(3,4,5)$ & $(4,5,6)$ \\
Slope & $(1 / 3,1 / 2,1 / 1)$ & $(1,1,1)$ & $(1,2,3)$ & $(2,3,4)$ & $(3,4,5)$ \\
Surface roughness & $(1 / 4,1 / 3,1 / 2)$ & $(1 / 3,1 / 2,1 / 1)$ & $(1,1,1)$ & $(1,2,3)$ & $(2,3,4)$ \\
Soil & $(1 / 5,1 / 4,1 / 3)$ & $(1 / 4,1 / 3,1 / 2)$ & $(1 / 3,1 / 2,1 / 1)$ & $(1,1,1)$ & $(1,2,3)$ \\
Stream channel & $(1 / 6,1 / 5,1 / 4)$ & $(1 / 5,1 / 4,1 / 3)$ & $(1 / 4,1 / 3,1 / 2)$ & $(1 / 3,1 / 2,1 / 1)$ & $(1,1,1)$ \\
\hline
\end{tabular}

moderately steep, and strong slope. These classes were ordered as $6,5,4,3,2$, and 1 , respectively, as manifested in Table 5. Accordingly, the most important layer was the land cover as it has the highest weight value where it has already obtained the highest priority because the change in land cover highly controls the urban flash flood effect, for instance, urbanization leads to infiltration reduction. Slope layer followed the land cover (LC) due to its role in the accumulation and discharge of the water, followed by surface roughness. The soil and stream channel criteria have no order of importance. When the AHP model was applied, the weights of the soil and stream channel criteria were low, 0.1 
TABLE 4: The computed values of weights (priority vector), CI, RI, and CR for authors' opinions.

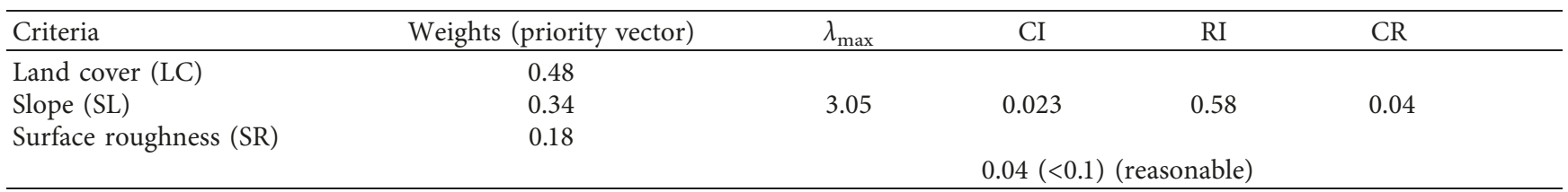

TABLE 5: The rating of the three criteria.

\begin{tabular}{|c|c|c|c|}
\hline Parameters & Relative weight & Reclassified parameter & Ranking \\
\hline \multirow{5}{*}{ Land cover (LC) } & \multirow{5}{*}{0.48} & Roads & 7 \\
\hline & & Building & 5 \\
\hline & & Quarry & 4 \\
\hline & & Bare soil & 1 \\
\hline & & Desert & 1 \\
\hline \multirow{6}{*}{ Slope (SL) } & \multirow{6}{*}{0.34} & Near level & 6 \\
\hline & & Very gentle slopes & 5 \\
\hline & & Gentle slopes & 4 \\
\hline & & Moderate slope & 3 \\
\hline & & Moderately steep & 2 \\
\hline & & Strong slope & 1 \\
\hline \multirow{3}{*}{ Surface roughness (SR) } & \multirow{3}{*}{0.18} & Build up (building and roads) & 7 \\
\hline & & Bare land (sand) & 5 \\
\hline & & Farmland (crop and pasture) & 1 \\
\hline
\end{tabular}

and 0.06, respectively. However, according to FAHP results which cater to the uncertainties, the final weights for the soil and stream channel criteria equal zero. Thus, we can consider that we have only three criteria and we have to neglect the other two ones.

The map of food-vulnerable area was extracted by multiplying the weight value assigned to each layer by the rank value given to the classes of that layer and finally by adding up the products. The following equation was used to compute the vulnerability index:

vulnerability index $=0.48 \times \mathrm{LC}+0.34 \times \mathrm{SL}+0.18 \times \mathrm{SR}$.

\subsection{Spatial Distribution of Flood Vulnerability Mapping.} Flood vulnerability mapping resulted from AHP will be assessed based on the change detection of the Sentinel-2 images. Flood susceptible area of the Ras Ghareb city is localized by the FAHP method (Figure 11). It was classified into four vulnerable classes, e.g., very high, high, moderate, and low. The results summarized that area $\mathrm{A}$, which represented $15 \%$ of the total area of the city, was classified into the aforementioned categories by $10.12,61.06,24.54$, and 2.88 ha, respectively, while area $\mathrm{B}$ had $80.58,212.99,155.25$, and 13.31 ha, respectively, which exhibited $72 \%$. Finally area $\mathrm{C}$ generated 15.23, 42.07, 28.61, and 3.11 ha, respectively, which occupied 13\% (Figure 12). According to Table 6, most of the areas $\mathrm{A}, \mathrm{B}$, and $\mathrm{C}$ lie in the very high and high risk zones with $72 \%, 63 \%$, and $64 \%$ ratio of their total area, respectively. Figure 13 illustrates that the destroyed roads and water bodies coincide with very high and high hazard.
As mentioned before, the FAHP method is combined with a geographical information system (GIS) for flood risk analysis and evaluation in the flood-prone area. Using such a GIS weighted overlay analysis map as an index, local governments, flood risk managers, and other decision-makers can act to prepare for probable flooding when it rains, or on the contrary, proactively encourage convenient land use policy that will minimize threat to lives and properties owing to flooding. Thus, the FAHP model is an alternative solution in case of unavailable satellite image data (Sentinel-2) before and after the flash flood perhaps due to the clouds in the winter (during the flood event). Hence, we can initially evaluate the economic losses from flooding. To establish an early warning system, some main elements need to be monitored like rainfall rate, soil moisture, and LUCC in addition to an assessment of the present protective works. Now, we can evaluate if these works are enough during the rainfall. If not, FAHP plays its vital role in the evacuation of the risky areas and direct them to the safe ones. The protection works may not be enough over the time due to the rapid climate change; thus the inactive basins, which have been neglected and have not been protected, may start vitality. As of 2012, the first early warning system used in Arab nations is being utilized and tested by the Water Resources Research Institute in Cairo, Egypt [34]. This system delivers a warning to registered residents at two different stages: the first warning is delivered after rainfall levels reach $10 \mathrm{~mm}$ within a six-hour period, and the second warning is delivered when precipitation levels reach $15 \mathrm{~mm}$. These warnings are delivered via e-mail, but will be delivered via SMS text message in the future [34]. This type of wide 


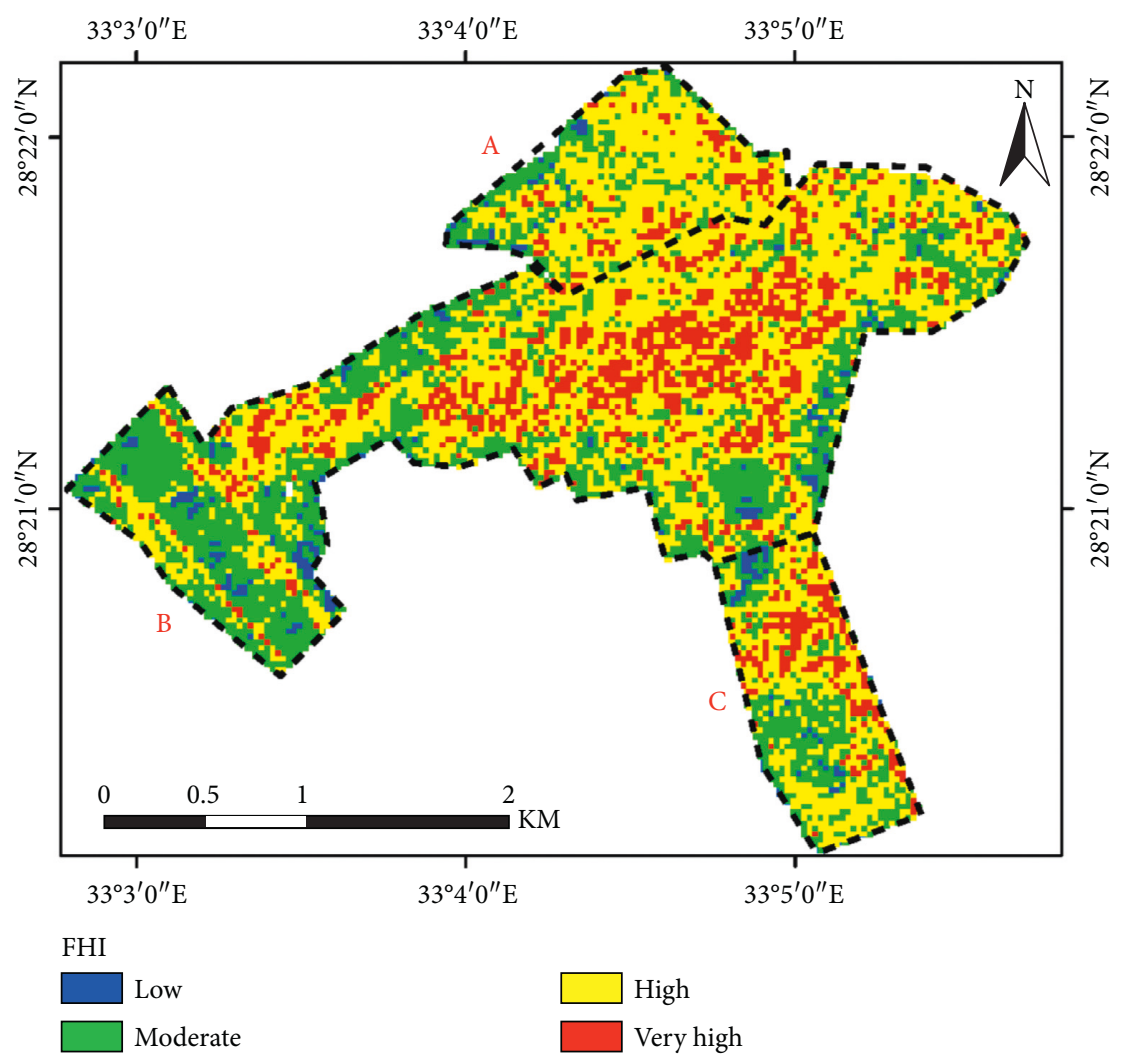

Figure 11: Flood susceptible area of the Ras Ghareb city.

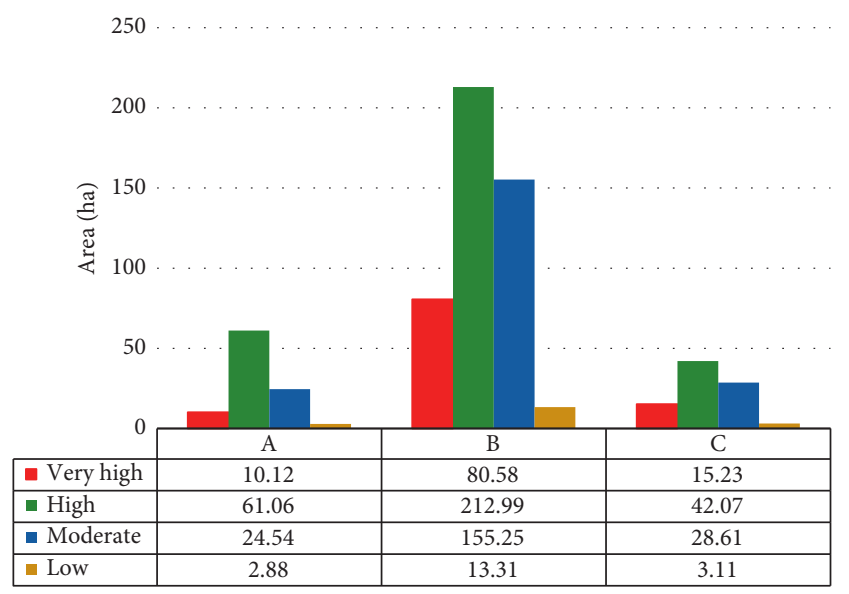

Figure 12: Categorization of each area.

warning system would benefit the residents of the Ras Ghareb city to evacuate in case of emergency.

\section{Conclusions}

In this work, we used a conceptual methodology based on low-cost solution to localize the destroyed areas. This paper can be concluded as follows:

Firstly, the change detection between the two Sentinel-2 satellite images (before and after the flash flood) is implemented. The destroyed area is analyzed by dividing the city into three zones A, B, and C. Areas of A and B are the most influenced ones owing to being the lowest areas; in addition, being built-up, areas reduce infiltration capacity and increase runoff of paved areas.

Secondly, Sentinel-2 images are appropriate for studying the evaluation of the flash flood effect on cities, determining destruction of roads network and detecting position of ephemeral water bodies but destroyed buildings require capturing ultrahigh spatial resolution images using the UAV.

In contrast, some satellites such as Landsat and Aster do not have fast revisit (16-day revisit time) and also spatial resolution lower than Sentinel-2. Although MODIS has higher temporal resolution than Sentinel-2 satellite, its spatial resolution is low. As a result, it cannot be used to determine the fine destroyed area like roads and detect water bodies in cities. The UAV is indeed the suitable solution to accurately delineate the urban flash flood impacts with avoidance of its disadvantages.

Thirdly, the FAHP model is applied to identify areas susceptible to flash flooding and produce flood vulnerability map with catering to the uncertainties in data and analysis. The most important layer according to the final weight was defined as the land cover, followed by slope and surface roughness, respectively, while soil and stream channel criteria were neglected $(W=0)$. The flood vulnerability map is classified into four levels of risk: very high, high, moderate, and low.

The FAHP model is an effective solution in case of unavailable Sentinel-2 satellite images or ultrahigh spatial resolution images (UAV) during the flood event perhaps due 
TABLE 6: Categorization percentage for each area.

\begin{tabular}{lccccccc}
\hline & Very high (\%) & High (\%) & Moderate (\%) & Low (\%) & Percentage & Very high-high (\%) & Moderate-low (\%) \\
\hline Area (A) & 10 & 62 & 25 & 3 & 100 & 72 & 28 \\
Area (B) & 17 & 46 & 34 & 3 & 100 & 63 & 37 \\
Area (C) & 17 & 47 & 32 & 4 & 100 & 64 & 36 \\
\hline
\end{tabular}

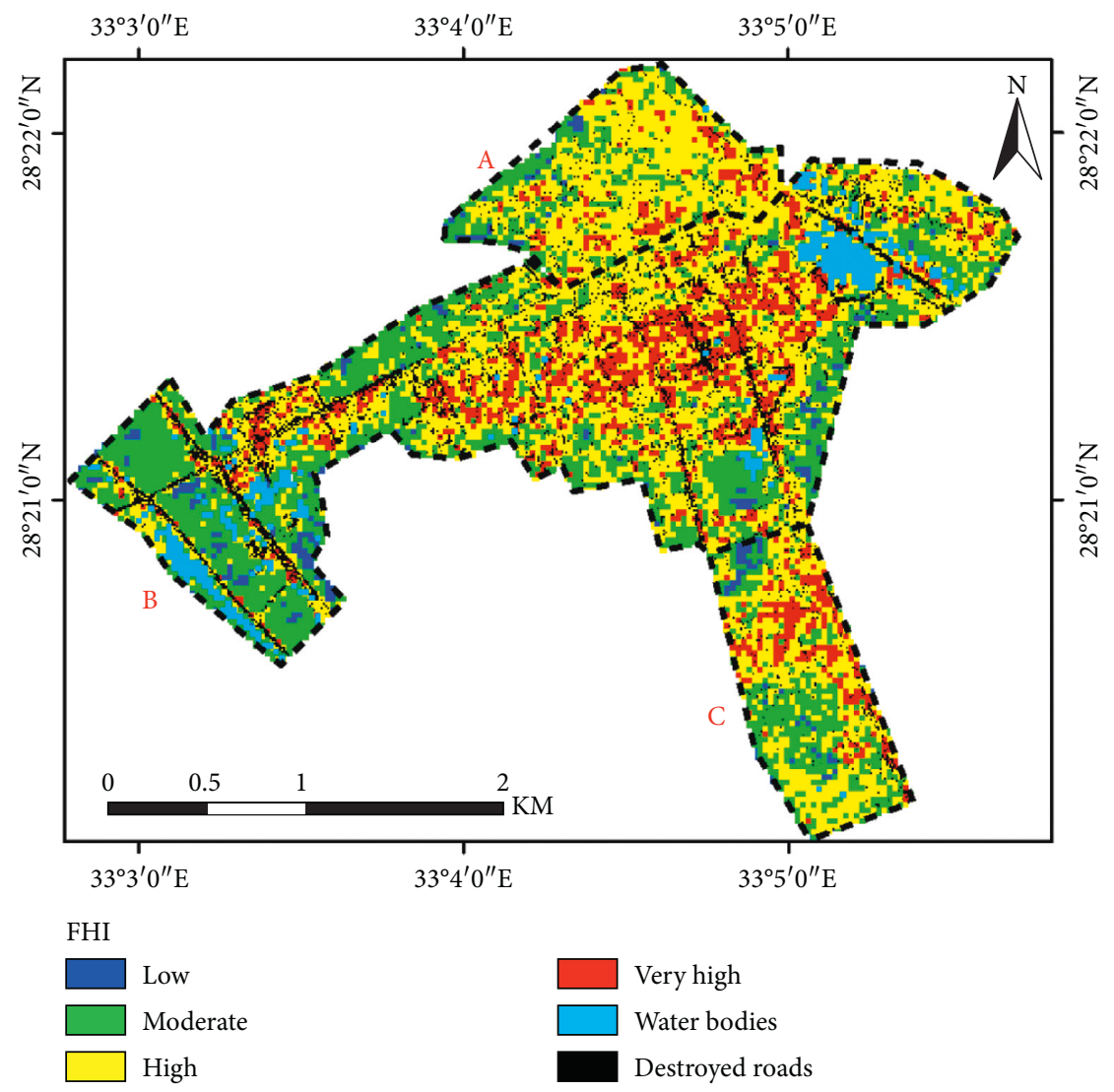

FIgURE 13: The coincidence of the destroyed roads and the water bodies with the very high and high hazard.

to the clouds. Using such a GIS weighted overlay analysis map as an index, local governments, flood risk managers, and other decision-makers can act to prepare for probable flooding when it rains, or on the contrary, proactively encourage convenient land use policy that will minimize threat to lives and properties owing to flooding.

Finally, the photos and videos from social media and Internet webpages prove their benefit in improving the mapping of the flooded areas. Furthermore, the geometric design review of the road before its implementation is crucial to ensure that its path is outside the catchment to avoid transferring flash floodwater [8].

\section{Data Availability}

The Sentinel-2 satellite data images used to support the findings of this study are accessible through https:// earthexplorer.usgs.gov/ (S2A_OPER_MSI_L1C_TL_SGS 20161102T084346_20161102T134833_A007125_T36RWS_N 02_04_01 and S2A_OPER_MSI_L1C_TL_SGS_20161013T 083346_20161013T121317_A006839_T36RWS_N02_04_01).
The digital soil map data, SRTM DEM data, and helicopter photos data used to support the findings of this study are obtained from Egyptian Geological Authority, https:// earthexplorer.usgs.gov/, and https://egyptianchronicles. blogspot.sg/2016/10/it-is-time-for-annual-heavy-rains-in. html, respectively.

\section{Conflicts of Interest}

The authors declare that they have no conflicts of interest.

\section{Acknowledgments}

We would like to thank Professor Li Xuxiang for the continuous support and also Dr. Hou Kang for his help and Chinese Scholarship Council for financial support. Finally, we thanked the municipal government that helped us clarify the extent of flood damage. This work was funded by the Ministry of Science and Technology of the People's Republic of China (2013FY112500). 


\section{Supplementary Materials}

(1) Visual interpretation. (2) Band combinations. (3) Direction of water flow. (4) Flood inundation mapping. (5) Monitor rainfall. (6) An advantage of helicopter images and geolocated photos and disadvantage of Sentinel-2 images. (7) Videos links. (Supplementary Materials)

\section{References}

[1] X. Lin, "Flash floods in arid and semi-arid zones," in Technical Documents in Hydrology, no. 23, UNESCO, Paris, France, 1999.

[2] M. Amadio, J. Mysiak, L. Carrera, and E. Koks, "Improving flood damage assessment models in Italy," Natural Hazards, vol. 82, no. 3, pp. 2075-2088, 2016.

[3] M. A. Clement, C. G. Kilsby, and P. Moore, "Multi-temporal synthetic aperture radar flood mapping using change detection," Journal of Flood Risk Management, vol. 11, no. 2, pp. 152-168, 2017.

[4] M. S. Rahman and L. Di, "The state of the art of spaceborne remote sensing in flood management," Natural Hazards, vol. 85, no. 2, pp. 1223-1248, 2017.

[5] J. Amini, "A method for generating floodplain maps using IKONOS images and DEMs," International Journal of Remote Sensing, vol. 31, no. 9, pp. 2441-2456, 2010.

[6] Y. Wang, J. D. Colby, and K. A. Mulcahy, "An efficient method for mapping flood extent in a coastal floodplain using landsat TM and DEM data," International Journal of Remote Sensing, vol. 23, no. 18, pp. 3681-3696, 2002.

[7] T. Gerl, M. Bochow, and H. Kreibich, "Flood damage modeling on the basis of urban structure mapping using highresolution remote sensing data," Water, vol. 6, no. 8, pp. 2367-2393, 2014.

[8] D. Giordan, D. Notti, A. Villa et al., "Low cost, multiscale and multi-sensor application for flooded area mapping," Natural Hazards and Earth System Sciences, vol. 18, no. 5, pp. 14931516, 2018.

[9] D. E. Alsdorf, E. Rodríguez, and D. P. Lettenmaier, "Measuring surface water from space," Reviews of Geophysics, vol. 45, no. 2, 2007.

[10] S. Schlaffer, P. Matgen, M. Hollaus, and W. Wagner, "Flood detection from multi-temporal SAR data using harmonic analysis and change detection," International Journal of Applied Earth Observation and Geoinformation, vol. 38, pp. 15-24, 2015.

[11] Q. Feng, J. Liu, and J. Gong, "Urban flood mapping based on unmanned aerial vehicle remote sensing and random forest classifier-a case of Yuyao, China," Water, vol. 7, no. 4, pp. 1437-1455, 2015.

[12] A. Rimba, M. Setiawati, A. Sambah, and F. Miura, "Physical flood vulnerability mapping applying geospatial techniques in Okazaki city, aichi prefecture, Japan," Urban Science, vol. 1, no. 1, p. 7, 2017.

[13] M. Gianinetto and P. Villa, "Mapping hurricane Katrina's widespread destruction in New Orleans using multisensor data and the normalized difference change detection (NDCD) technique," International Journal of Remote Sensing, vol. 32, no. 7, pp. 1961-1982, 2011.

[14] C. Kuenzer, H. Guo, J. Huth, P. Leinenkugel, X. Li, and S. Dech, "Flood mapping and flood dynamics of the Mekong Delta: ENVISAT-ASAR-WSM based time series analyses," Remote Sensing, vol. 5, no. 2, pp. 687-715, 2013.
[15] F. Gascon, C. Bouzinac, O. Thépaut et al., "Sentinel-2A calibration and products validation status," Remote Sensing, vol. 9, no. 6, p. 584, 2017.

[16] J. Hoffmann and D. Walter, "How complementary are SRTM$\mathrm{X}$ and-C band digital elevation models?," Photogrammetric Engineering \& Remote Sensing, vol. 72, no. 3, pp. 261-268, 2006.

[17] J. A. Slater, G. Garvey, C. Johnston et al., "The SRTM data "finishing" process and products," Photogrammetric Engineering \& Remote Sensing, vol. 72, no. 3, pp. 237-247, 2006.

[18] C. Huggel, D. Schneider, P. J. Miranda, H. D. Granados, and A. Kääb, "Evaluation of ASTER and SRTM DEM data for lahar modeling: a case study on lahars from Popocatépetl volcano, Mexico," Journal of Volcanology and Geothermal Research, vol. 170, no. 1-2, pp. 99-110, 2008.

[19] A. Jarvis, H. I. Reuter, A. Nelson, and E. Guevara, Hole-filled SRTM for the globe, 2008, Version 4. available from the CGIAR-CSI SRTM 90m Database.

[20] J. Fohringer, D. Dransch, H. Kreibich, and K. Schröter, "Social media as an information source for rapid flood inundation mapping," Natural Hazards and Earth System Sciences, vol. 15, no. 12, pp. 2725-2738, 2015.

[21] J. F. Rosser, D. G. Leibovici, and M. J. Jackson, "Rapid flood inundation mapping using social media, remote sensing and topographic data," Natural Hazards, vol. 87, no. 1, pp. 103120, 2017.

[22] K. C. Hung, M. Kalantari, and A. Rajabifard, "Methods for assessing the credibility of volunteered geographic information in flood response: a case study in Brisbane, Australia," Applied Geography, vol. 68, pp. 37-47, 2016.

[23] E. Schnebele and G. Cervone, "Improving remote sensing flood assessment using volunteered geographical data," Natural Hazards and Earth System Sciences, vol. 13, no. 3, pp. 669-677, 2013.

[24] H. Xu, "Modification of normalised difference water index (NDWI) to enhance open water features in remotely sensed imagery," International Journal of Remote Sensing, vol. 27, no. 14, pp. 3025-3033, 2006.

[25] Y. Mostafa, "Comparison of Land cover change detection methods using SPOT images," Master of Science, Department of Civil Engineering, Assiut University, Asyut, Egypt, 2006.

[26] M. Story and R. G. Congalton, "Accuracy assessment: a user's perspective," Photogrammetric Engineering and Remote Sensing, vol. 52, no. 3, pp. 397-399, 1986.

[27] R. Al-Adamat, A. Diabat, and G. Shatnawi, "Combining GIS with multicriteria decision making for siting water harvesting ponds in Northern Jordan," Journal of Arid Environments, vol. 74, no. 11, pp. 1471-1477, 2010.

[28] R. C. Srivastava, "Methodology for optimizing design of integrated tank irrigation system," Journal of Water Resources Planning and Management, vol. 122, no. 6, pp. 394-402, 1996.

[29] T. L. Saaty, The Analytic Process: Planning, Priority Setting, Resources Allocation, McGraw, New York, NY, USA, 1980.

[30] H. Deng, "Multicriteria analysis with fuzzy pairwise comparison," International Journal of Approximate Reasoning, vol. 21, no. 3, pp. 215-231, 1999.

[31] B. Ahmed, "Landslide susceptibility modelling applying userdefined weighting and data-driven statistical techniques in Cox's Bazar municipality, Bangladesh," Natural Hazards, vol. 79, no. 3, pp. 1707-1737, 2015.

[32] A. K. Saraf and P. R. Choudhury, "Integrated remote sensing and GIS for groundwater exploration and identification of artificial recharge sites," International Journal of Remote sensing, vol. 19, no. 10, pp. 1825-1841, 1998. 
[33] J. Malczewski, GIS and Multicriteria Decision Analysis, John Wiley \& Sons, Hoboken, NJ, USA, 1999.

[34] J. Cools, P. Vanderkimpen, G. E. Afandi et al., "An early warning system for flash floods in hyper-arid Egypt," Natural Hazards and Earth System Sciences, vol. 12, no. 2, pp. 443-457, 2012. 


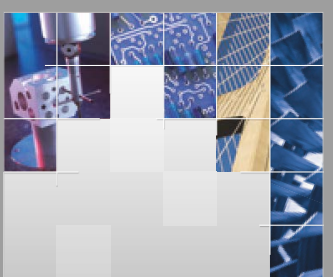

\section{Enfincering}
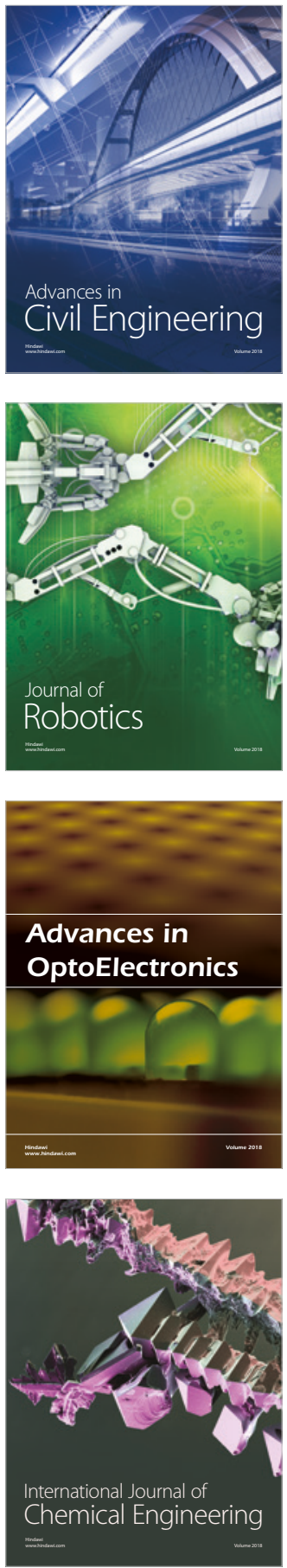

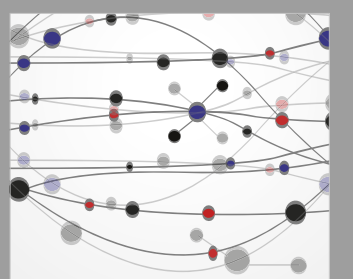

\section{Rotating \\ Machinery}

The Scientific World Journal

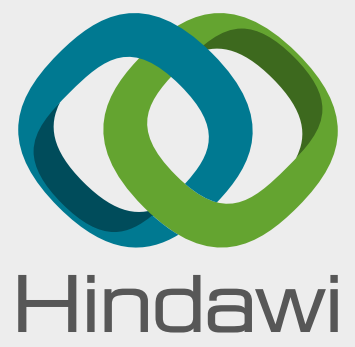

Submit your manuscripts at

www.hindawi.com
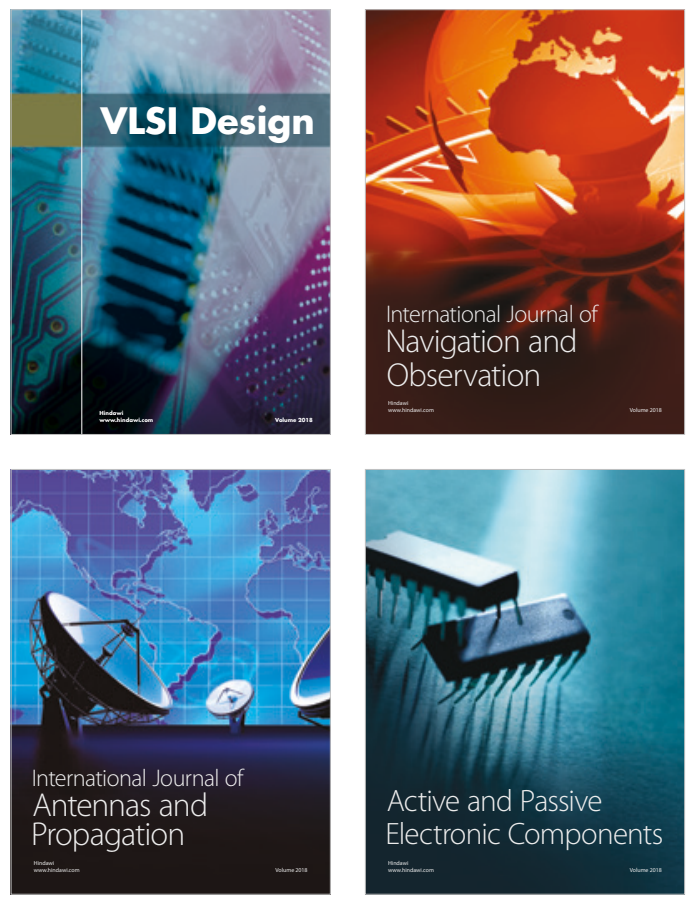
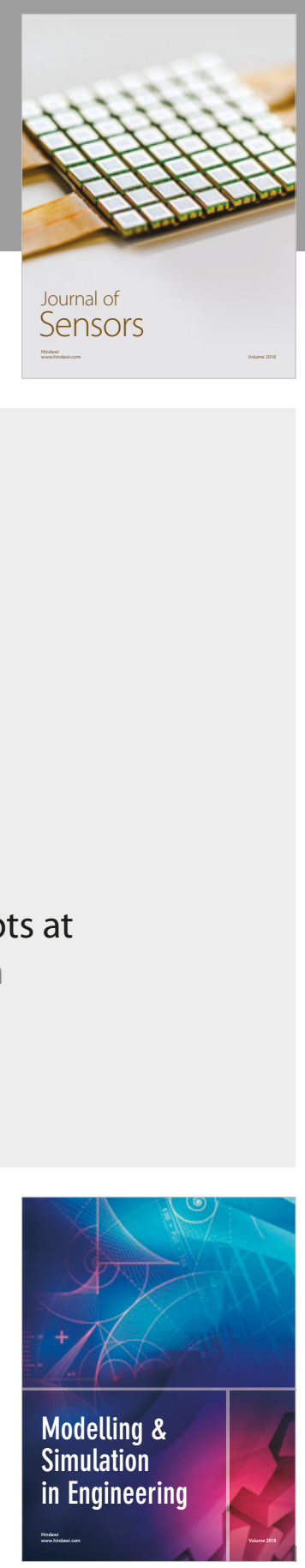

\section{Advances \\ Multimedia}
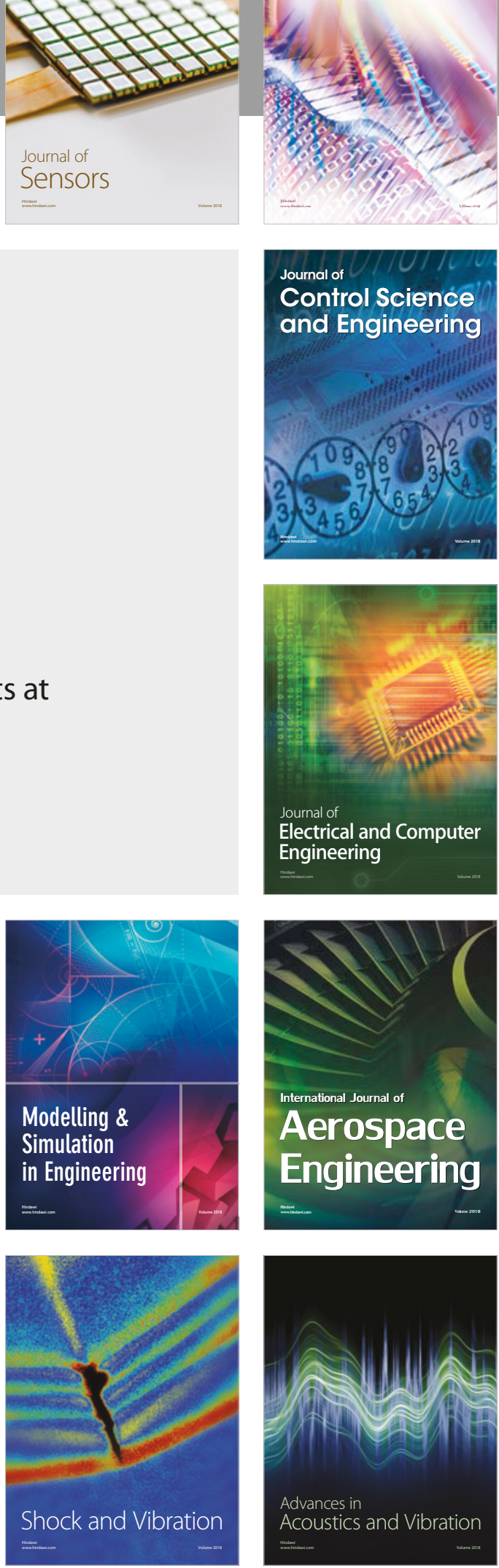